\title{
Multivariate Volatility In Environmental Finance
}

\author{
${ }^{\mathrm{a}}$ Hoti, S., ${ }^{\mathrm{a}}$ M. McAleer and ${ }^{\mathrm{b}} \underline{\mathrm{L} . L . \text { Pauwels }}$

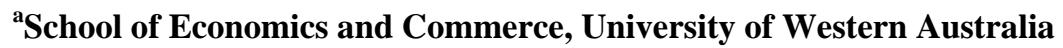 \\ ${ }^{b}$ Economics Section, Graduate Institute of International Studies, Geneva, Email: pauwels0@hei.unige.ch
}

Keywords: Environmental risk; financial risk; multivariate conditional volatility; persistence; shocks; symmetry; spillovers.

\section{EXTENDED ABSTRACT}

There exist several important benchmark indices in environmental finance, some computed by wellknown financial index providers such as the Dow Jones group or the FTSE group, and others by independent agencies specializing in environmental and ethical issues in finance. The main feature of these sustainability indices is that they are constructed from a selection of financial stocks according to sustainable economic, environmental, social and ethical criteria. The resulting sustainability indices are meant to be representative of the diversity of industries and size of firms in the market, at the national, regional and international level. This paper builds on earlier empirical work investigating conditional volatility or risk inherent in two major financial time-series indices featuring ethical and environmental screening. Moreover, the trends and volatility of two prominent financial indexes, namely DJIA and S\&P500, are analysed in the same manner to provide a comparison of the time series performance of the two types of indexes. We examine symmetric and asymmetric effects of shocks at the multivariate level, and we investigate the presence and the importance of multivariate effects in conditional volatility in each of these indices as a way to analyse their relative inherent risk. We further investigate empirically the existence of risk spillovers across these four indexes.

Environmental issues have become increasingly important in economic research and policy for sustainable development. Such issues are tracked by the Dow Jones Sustainable Indexes (DJSI) and Ethibel Sustainability Index (ESI) through financial market indexes that are derived from the Dow Jones Global Indexes and Standard \& Poor's (S\&P). The environmental sustainability activities of firms are assessed using criteria in three areas, namely economic, environmental and social. Risk (or uncertainty) is analysed empirically through the use of conditional volatility models of investment in sustainability-driven firms that are selected through the DJSI and ESI (for further details see Hoti, McAleer and Pauwels (2005a,b)).
In this paper, we analyse empirically the timevarying conditional variance (or risk) associated with investing in leading sustainability-driven firms using multivariate models of conditional volatility. As the concept of environmental risk has had several different interpretations in the economics literature, we use the definition given in Hoti, McAleer and Pauwels (2005a):

"Environmental risk is the volatility associated with the returns to a variety of environmental sustainability indexes."

Models of the conditional variance, or risk, of a time series have long been popular in the financial econometrics literature. Three of the most popular models to capture the time-varying volatility in financial time series are the Generalised Autoregressive Conditional Heteroscedasticity (GARCH) model of Engle (1982) and Bollerslev (1986), the GJR model of Glosten, Jagannathan and Runkle (1992), and the Exponential GARCH (EGARCH) model of Nelson (1991). Multivariate extensions of GARCH models are also available in the literature, such as the Constant Conditional Correlation (CCC) GARCH model Bollerslev (1990), Vector Autoregressive Moving Average GARCH (VARMA-GARCH) model of Ling and McAleer (2003), and VARMA Asymmetric GARCH (VARMA-AGARCH) model of Hoti, Chan and McAleer (2002).

To date there seem to have been only a few empirical studies of such sustainability indexes. It is only recently that time-varying models of heteroscedasticity have been applied to sustainability indexes (see Hoti, McAleer and Pauwels (2005a)). The plan of the paper is as follows. Section 1 presents the environmental sustainability indexes, namely Dow Jones Sustainability and the Ethibel Sustainability Index and discusses their key features. Multivariate conditional volatility models for daily indexes are presented in Section 2. The data are described in Section 3, and the empirical results are analysed in Section 4. Some concluding remarks are given in Section 5. 


\section{SUSTAINABILITY INDEXES}

\subsection{Dow Jones Sustainability Indexes (DJSI)}

Dow Jones Sustainability Indexes (DJSI) commenced in 1998, and report on the financial performance of leading sustainability-driven firms worldwide (for a discussion of the DJSI indexes, see Hoti, McAleer and Pauwels (2005a,b)). These sustainability indexes were created by the Dow Jones Indexes, STOXX Limited and the SAM group.

The main purpose of the DJSI is to provide asset managers with a benchmark to manage sustainability portfolios, and develop financial products and services that are linked to sustainable economic, environmental and social criteria. DJSI indexes quantify the development and promotion of sustainable values on the environment and society by the business community. They also enable the promotion of sustainability within the private sector by informing investors about firms that behave in an environmentally sustainable manner.

As for the Dow Jones Global Indexes, the DJSI features the same methods for calculating, reviewing and publishing data. The DJSI is used in 14 countries, with 50 licenses having been sold to asset managers. There are two sets of DJSI indexes, namely the DJSI World and the DJSI STOXX (which is a pan-European index). The latter index is also subdivided into another regional index, namely DJSI EURO STOXX, which accounts solely for Euro-zone countries. Dow Jones Sustainability World Index (DJSI World) is constructed by selecting the leading $10 \%$ of sustainability firms (which number more than 300) in the Dow Jones Global Index, which covers 59 industries over 34 countries. The composite DJSI World is available in four specialised subset indexes, which exclude companies that generate revenue from (1) tobacco, (2) gambling, (3) armaments or firearms, and (4) alcohol, in addition to the three previously mentioned items.

The DJSI World is reviewed annually and quarterly to ensure consistency. It also accommodates potential changes in the behaviour and status of companies which could affect their sustainability performance (such as bankruptcies, mergers and takeovers). The index comprises companies from 60 industry groups and 18 market sectors.

\subsection{Ethibel Sustainability Indices (ESI)}

The Ethibel Sustainability Index (ESI) is composed of four regional indices, namely ESI Global, ESI Americas, ESI Europe and ESI Asia-Pacific. The indices are calculated and maintained by Standard \& Poor's (S\&P), following S\&P methodology. The ESI regional indices are designed in such a way as to approximate the sector weights of the S\&P Global 1200, such that each regional sub-component accounts for a share of ESI Global. Specifically, Asia-Pacific accounts for $11 \%$ in ESI Global, the Americas 57\%, and Europe 32\%.

The ESI Global tracks 162 companies in 19 different countries. In the same manner as the Dow Jones Sustainability Indexes (DJSI), the Ethibel Sustainability Indices are calculated as both price and returns indices in USD and EUR, yielding a total of 16 indices (further information about the ESI and the regional ESI can be found at www.ethibel.org).

The selection of companies is based on a set of positive criteria which examine the best-in-sector and best-in-region companies. The screening and research methodology concentrates on two elements of corporate social responsibility, namely: (1) sustainable development, guiding the research on a specific company over environmental, internal and external social, economic and ethical aspects and policy; and (2) stakeholder involvement, which translates to dialogue between the ESI and the stakeholders during the research.

\section{MULTIVARIATE MODELS OF CONDITIONAL VOLATILITY FOR SUSTAINABILITY INDEXES}

The primary empirical purpose of the paper is to model the DJSI and ESI indexes and their associated volatility for the period 31 December 1997 to 1 September 2005. This approach is based on Engle's (1982) development of time-varying volatility (or uncertainty) using the autoregressive conditional heteroskedasticity (ARCH) model, and subsequent developments associated with the ARCH family of models (see, for example, the recent survey by Li, Ling and McAleer (2002)). Of the wide range of univariate conditional volatility models, the two most popular have been the symmetric generalised ARCH (GARCH) model of Bollerslev (1986) and the asymmetric GARCH (or GJR) model of Glosten, Jagannathan and Runkle (1992), especially for the analysis of financial data. Several other theoretical developments have recently been suggested by Wong and Li (1997), Hoti, Chan and McAleer (2002), Ling and McAleer (2002a,b) and Ling and McAleer (2003). A comparison of the structural and statistical properties of alternative univariate and multivariate conditional and stochastic volatility models is given in McAleer (2005).

Two constant conditional correlation models, namely the symmetric VARMA-GARCH model of Ling and McAleer (2003), and the asymmetric VARMA-GARCH (or VARMA-AGARCH) model of Hoti, Chan and McAleer (2002), are estimated 
using daily data on two sustainability indexes and two financial indexes. Consider the following specification for the return on a stock index or on a financial asset (as measured in log-differences), $y_{t}$ :

$$
\begin{aligned}
& y_{t}=E\left(y_{t} \mid \mathfrak{I}_{t-1}\right)+\varepsilon_{t}, \quad t=1, \ldots, n \\
& \varepsilon_{t}=D_{t} \eta_{t}
\end{aligned}
$$

where $\mathfrak{I}_{t}$ is the information set available to time $t$, $y_{t}=\left(y_{1 t}, \ldots, y_{m t}\right)^{\prime}$ measures returns for different indexes, $\quad \eta_{t}=\left(\eta_{1 t}, \ldots, \eta_{m t}\right)^{\prime}$ is a sequence of independently and identically distributed random vectors that is obtained from standardising the shocks to index returs, $\varepsilon_{t}$, using the standardisation $D_{t}=\operatorname{diag}\left(h_{1 t}^{1 / 2}, \ldots, h_{m t}^{1 / 2}\right), m(=4)$ is the number of index returns, and $t=1, \ldots, 2802$ daily observations for the period 31/12/ 1997 to 1/09/2005.

The constant conditional correlation (CCC) GARCH model of Bollerslev (1990) assumes that the conditional variance of the shocks to index return $i$, $i=1, \ldots, m$, follows a univariate $\operatorname{GARCH}(\mathrm{r}, \mathrm{s})$ process, that is,

$$
h_{i t}=\omega_{i}+\sum_{l=1}^{r} \alpha_{i l} \varepsilon_{i t-l}^{2}+\sum_{l=1}^{s} \beta_{i l} h_{i t-l}
$$

where $\alpha_{i l}$ represents the ARCH effects, or the short run persistence of shocks to index return $i$, and $\beta_{i l}$ represents the GARCH effects, or the contribution of such shocks to long run persistence. This model assumes the independence of conditional variances, and hence no spillovers in volatility, across different index returns. Moreover, CCC does not accommodate the (possibly) asymmetric effects of positive and negative shocks on conditional volatility. It is important to note that $\Gamma=\left\{\rho_{i j}\right\}$ is the matrix of constant conditional correlations, in which $\rho_{i j}=\rho_{j i}$ for $i, j=1, \ldots, m$. Therefore, the multivariate effects are determined solely through the constant conditional correlation matrix.

Equation (2) assumes that a positive shock $\left(\varepsilon_{t}>0\right)$ has the same impact on the conditional variance, $h_{t}$, as a negative shock $\left(\varepsilon_{t}<0\right)$, but this assumption is often violated in practice. An extension of (2) to accommodate the possible differential impact on the conditional variance between positive and negative shocks is given by

$$
h_{i t}=\omega_{i}+\left(\sum_{l=1}^{r} \alpha_{i l}+\sum_{l=1}^{r} \gamma_{i l} I\left(\eta_{i t-l}\right)\right) \varepsilon_{i t-l}^{2}+\sum_{l=1}^{s} \beta_{i l} h_{i t-l}
$$

in which $\varepsilon_{i t}=\eta_{i t} \sqrt{h_{i t}}$ for all $i$ and $t$, and $I\left(\eta_{i t}\right)$ is an indicator variable such that

$$
I\left(\eta_{i t}\right)= \begin{cases}1, & \varepsilon_{i t}<0 \\ 0, & \varepsilon_{i t}>0\end{cases}
$$

As in (1), $\eta_{t}=\left(\eta_{1 t}, \ldots, \eta_{m t}\right)^{\prime}$ is a sequence of iid random vectors, with zero mean and covariance matrix $\Gamma$, so that $\varepsilon_{t}=D_{t} \eta_{t}$, in which $D_{t}$ depends only on $H_{t}=\left(h_{1 t}, \ldots, h_{m t}\right)$ '. As an extension of (3) to incorporate multivariate effects across equations, and hence spillovers in volatility across different index returns, it is necessary to define $h_{i t}$ to contain past information from $\varepsilon_{i t}, \varepsilon_{j t}, h_{i t}$ and $h_{j t}$ for $i, j=1, \ldots, m, i \neq j$.

Thus, the asymmetric VARMA $(p, q)-\operatorname{GARCH}(r, s)$, or VARMA-AGARCH, model of Hoti, Chan and McAleer (2002) is defined as follows:

$$
\Phi(L)\left(Y_{t}-\mu\right)=\Psi(L) \varepsilon_{t}
$$

$\varepsilon_{t}=D_{t} \eta_{t}$

$H_{t}=W+\left(\sum_{l=1}^{r} A_{l}+\sum_{l=1}^{r} C_{l} I\left(\eta_{t-1}\right)\right) \stackrel{r}{\varepsilon_{t}}+\sum_{l=1}^{s} B_{l} H_{t-l}$

The univariate constant-mean GJR model is obtained from (4)-(5) or by specifying $A_{l}, C_{l}$ and $B_{l}$ as diagonal matrices. The CCC model (1)-(2) is obtained from (4)-(5) by setting $A_{1}=\operatorname{diag}\left\{\alpha_{i l}\right\}$, $B_{l}=\operatorname{diag}\left\{\beta_{i l}\right\}$ and $C_{l}=0$ for $l=1, \ldots, r$, while the VARMA-GARCH model is obtained from (4)-(5) by setting $C_{l}=0$ for $l=1, \ldots, r$.

\section{DATA DESCRIPTION}

In this paper we select the DJSI World and ESI Global as two representative sustainability indexes. The indexes are available on both a daily and monthly basis from the Dow Jones Sustainability Indexes website (see http://www.sustainabilityindexes.com) and Ethibel Sustainability Index (see http://www.ethibel.org/ subs_e/4_index/main.html). They are calculated on a 7-day per week basis as the returns on the index, in both USD and EURO currencies. In this paper, we estimate models using only the daily data on the index denominated in USD, as daily data are more informative with regard to the existence of volatility. Moreover, we analyse daily USD returns on two prominent financial indexes, namely the Dow Jones Industrial Average (DJIA) and Standard \& Poor's 500 (S\&P500), also calculated on a 7-day per week basis. 
The empirical analysis in this paper involves two DJSI indexes and two financial indexes for the period 31 December 1997 to 1 September 2005. Levels and returns for each of the four indexes, namely DJSI World, ESI Global, DJIA and S\&P500, are presented in Figure 1-2. Apart from DJIA, the patterns in both series are remarkably similar. There is a substantial clustering of returns for each series, with only the DJIA returns showing any differences from the remaining three series.

\section{EMPIRICAL RESULTS}

As shown in Figures 3-4, there is substantial volatility in each of the four series. Using the data on the daily indexes, the conditional mean is modelled in each case as an $\operatorname{ARMA}(1,1)$ process. Table 1 provides the ADF and Phillips-Perron (PP) unit root tests for the four indexes, as well as their logdifferences (or rates of return). It is clear that the indexes are non-stationary, while their rates of return are stationary.

In addition to estimating the conditional mean for each index, the VARMA-GARCH and VARMAAGARCH models are used to estimate the conditional volatility associated with the two types of indexes. On the basis of the univariate standardised shocks, the two multivariate models are used to estimate the conditional correlation coefficients of the daily index return shocks between the four indexes. This can provide useful information regarding the relationship between the indexes in terms of the shocks to index returns.

In this paper, the estimates of the parameters are obtained using the Berndt, Hall, Hall and Hausman (BHHH) (1974) in the EViews 5 econometric software package. Using the RATS 6 econometric software package yielded virtually identical results. Both the asymptotic and the Bollerslev-Wooldridge (1992) robust t-ratios are reported. In general, the robust t-ratios are smaller in absolute value than their asymptotic counterparts.

Table 2 reports the estimates of the VARMAGARCH model. Except for the DJIAs, the conditional mean estimates show significant dynamics for all four index returns. The estimates of the conditional variance for the two sustainability indexes show that the DJSI World index returns are affected by its own previous short run $\left(\alpha_{D J S}\right)$ and long run $\left(\beta_{\text {DJS }}\right)$ shocks, and previous short and/or long run shocks to both ESI Global and DJIA. On the other hand, the ESI Global index is affected only by its own long run ( $\left.\beta_{E S I}\right)$ shocks.

Regarding the financial indexes, the estimated results in Table 2 show that the DJIA index returns are affected by its own previous long run $\left(\beta_{D J}\right)$ shocks, and previous short run shocks to both DJSI World $\left(\alpha_{D J S}\right)$ and ESI Global $\left(\alpha_{E S I}\right)$. The S\&P500 index returns are affected only by previous short run shocks to ESI Global $\left(\alpha_{E S I}\right)$. Therefore, no own effects are observed for S\&P500 for the case of VARMA-GARCH.

Overall, volatility spillover effects are observed from ESI Global to the DJSI World, but not the reverse. Spillover effects are also observed from DJIA to DJSI World and from ESI Global to S\&P500. These results show that there are spillover effects between the two sustainability indexes and no spillover effects between the two financial indexes, with ESI Global being independent of shocks to other indexes. Shocks to the sustainability indexes affect the volatility of the financial indexes. There is only one case with spillover effects from financial index returns (DJIA) to sustainability index returns (DJSI World).

Estimates of the VARMA-AGARCH model are presented in Table 3. Unlike the previous table, insignificant dynamics are observed only for S\&P500 index returns. The estimates of the conditional variance show significant asymmetric effects of positive and negative index return shocks on the conditional volatility in all cases. In terms of the multivariate spillover effects on the conditional variance, the two sustainability indexes are only affected by their own previous short run and long run shocks. Similarly, the results in Table 3 show that the DJIA index return is only affected by its own previous short run and long run shocks, while the S\&P500 index return is affected by its previous short and long run shocks, and previous short and/or long run shocks to ESI Global and DJIA. Unlike the case of the VARMA-GARCH model, no volatility spillover effects are observed for the risk return indexes, except for S\&P500.

The estimated conditional volatility for the DJSI World, ESI Global, DJIA and S\&P500 for VARMA-GARCH and VARMA-AGARCH are plotted in Figure 3-4. Overall, there is strong evidence of volatility clustering, with the presence of some outliers and/or extreme observations. Moreover, the estimated conditional volatilities for the four index returns for VARMA-GARCH differ from their VARMA-AGARCH counterpart. This is because no spillover effects were found, in general, while significant asymmetric effects of positive and negative index return shocks on the conditional volatility were observed for all four indexes.

Using the estimated index return standardised shocks obtained from the two models, the conditional correlation coefficients for index return shocks are calculated and reported in Table 4. It is clear that the conditional correlations between the four index return shocks are very high and virtually 
identical for the two models. The highest conditional correlation holds for (DJIA, S\&P500) followed by (DJSI World, ESI Global). This implies that the two sustainability indexes are close substitutes in terms of the shocks to their index returns. The same holds for the two financial indexes, namely DJIA and S\&P500. Overall, these estimates suggest that the shocks from alternative index returns are similar.

\section{CONCLUSION}

Overall, the VARMA-GARCH results showed that there were spillover effects between the two sustainability indexes and no spillover effects between the two financial indexes, with ESI World being independent of shocks to other indexes. Shocks to the sustainability indexes affected the volatility of the financial indexes. There was only one case with spillover effects from financial index returns (DJIA) to sustainability index returns (DJSI World). While for the VARMA-AGARCH model, no volatility spillover effects are observed for the risk return indexes, except for S\&P500.

The conditional correlations between the four index return shocks were very high and virtually identical for the two models. This implies that the two sustainability indexes are close substitutes in terms of the shocks to their index returns. The same holds for the two financial indexes, namely DJIA and S\&P500. Overall, these estimates suggested that the shocks from alternative index returns are similar.

\section{AKNOWLEDGEMENTS}

The authors would like to thank Kathrin Füllemann of SAM Indexes GmbH for helpful information. The first two authors wish to acknowledge the financial support of the Australian Research Council.

\section{REFERENCES}

Berndt, E.K., B.H. Hall, R.E. Hall and J.A. Hausman (1974), Estimation and inference in nonlinear structural models, Annals of Economic and Social Measurement, 3, 653-665.

Bollerslev, T. (1986), Generalized Autoregressive Conditional Heteroskedasticity, Journal of Econometrics, 31, 307-327.

Bollerslev, T. (1990) Modelling the coherence in short-run nominal exchange rate: A multivariate generalized ARCH approach, Review of Economics and Statistics, 72, 498-505.

Bollerslev, T. and J.M. Wooldridge (1992), Quasimaximum likelihood estimation and inference in dynamic models with time-varying covariances, Econometric Reviews, 11, 143-173.
Dow Jones Sustainability Indexes (2005), Dow Jones Sustainability World Indexes Guide, http://www.sustainability-indexes.com.

Engle, R.F. (1982), Autoregressive Conditional Heteroscedasticity with Estimates of the Variance of United Kingdom Inflation, Econometrica, 50, 987-1007.

Ethibel Sustainability Index (2005), Selection Criteria, Constituents and Performance, available http://www.ethibel.org/subs_e/4_ index/main.html.

Glosten, L., R. Jagannathan and D. Runkle (1992), On the Relation Between the Expected Value and Volatility of Nominal Excess Returns on Stocks, Journal of Finance, 46, 1779-1801.

Hoti, S., F. Chan and M. McAleer (2002), Structure and asymptotic theory for multivariate asymmetric volatility: Empirical evidence for country risk ratings, paper presented to the Australasian Meeting of the Econometric Society, Brisbane, Australia, July 2002.

Hoti, S., M. McAleer and L.L. Pauwels (2005a), Modelling Environmental Risk, Environmental Modelling and Software, 20, 1289-1298.

Hoti, S., M. McAleer and L.L. Pauwels (2005b), Measuring Environmental Risk, to appear in Journal of Economic Surveys.

Li, W.K., S. Ling and M. McAleer (2002), Recent Theoretical Results for Time Series Models with GARCH Errors, Journal of Economic Surveys, 16, 245-269. Reprinted in M. McAleer and L. Oxley (eds.), Contributions to Financial Econometrics: Theoretical and Practical Issues, Blackwell, Oxford, 2002, pp. 9-33.

Ling, S. and M. McAleer (2002a), Necessary and Sufficient Moment Conditions for the GARCH(r,s) and Asymmetric Power GARCH(r,s) Models, Econometric Theory, 18, 722-729.

Ling, S. and M. McAleer (2002b), Stationarity and the Existence of Moments of a Family of GARCH Processes, Journal of Econometrics, 106, 109-117.

Ling, S. and M. McAleer (2003), Asymptotic Theory for a Vector ARMA-GARCH Model, Econometric Theory, 19, 278-308.

McAleer, M. (2005), Automated inference and learning in modeling financial volatility, Econometric Theory, 21, 232-261.

Nelson, D.B. (1991), Conditional heteroscedasticity in asset returns: A new approach, Econometrica, 59, 347-370.

Wong, H. and W.K. Li (1997), On a multivariate conditional heteroscedasticity model, Biometrika, 4, 111-123. 
Table 1: Unit Root Test Statistics for Daily Stock Indexes

\begin{tabular}{|l|c|c|}
\hline Indexes & ADF & Phillips-Perron \\
\hline DJSI World & -1.728 & -1.703 \\
ESI Global & -2.015 & -1.976 \\
DJIA & -2.822 & -2.810 \\
S\&P500 & -2.170 & -2.088 \\
\hline
\end{tabular}

Note: The simulated critical value at $1 \%$ level of significance is -3.961

\begin{tabular}{|l|c|c|}
\hline Indexes (Log-differences) & ADF & Phillips-Perron \\
\hline DJSI World & -23.777 & -47.260 \\
ESI Global & -23.800 & -48.225 \\
DJIA & -24.253 & -53.547 \\
S\&P500 & -25.016 & -54.102 \\
\hline
\end{tabular}

Note: The simulated critical value at $1 \%$ level of significance is -3.432

Table 2: VARMA-GARCH Spillover Effects for Four Indexes

\begin{tabular}{|c|c|c|c|c|c|c|c|c|c|c|c|c|}
\hline \multirow{2}{*}{ Data } & \multirow{2}{*}{\multicolumn{3}{|c|}{ Conditional Mean }} & \multicolumn{9}{|c|}{ Conditional Variance } \\
\hline & & & & \multicolumn{3}{|c|}{ Own Effects } & \multicolumn{6}{|c|}{$\begin{array}{ll}\text { Spillover Effects } \\
\end{array}$} \\
\hline \multirow{4}{*}{$\begin{array}{c}\text { DJSI } \\
\text { World }\end{array}$} & $\theta_{0}$ & $\theta_{1}$ & $\theta_{2}$ & $\omega$ & $\alpha$ & $\beta$ & $\alpha_{E S I}$ & $\beta_{E S I}$ & $\alpha_{D J I}$ & $\beta_{D J I}$ & $\alpha_{S P}$ & $\beta_{S P}$ \\
\hline & 2.E-04 & -0.276 & 0.374 & 5.E-07 & 0.018 & 0.973 & 0.001 & -0.004 & 0.026 & -0.029 & -0.010 & 0.016 \\
\hline & 0.945 & -1.540 & 2.149 & 5.219 & 4.728 & 16.090 & 0.793 & -1.973 & 4.169 & -4.494 & -1.663 & 2.710 \\
\hline & 0.941 & -1.634 & 2.310 & 6.323 & 2.301 & 8.834 & 0.830 & -2.190 & 2.009 & -2.044 & -0.831 & 1.232 \\
\hline \multirow{4}{*}{$\begin{array}{c}\text { ESI } \\
\text { Global }\end{array}$} & $\theta_{0}$ & $\theta_{1}$ & $\theta_{2}$ & $\omega$ & $\alpha$ & $\beta$ & $\alpha_{D J S}$ & $\beta_{D J S}$ & $\alpha_{D J I}$ & $\beta_{D J I}$ & $\alpha_{S P}$ & $\beta_{S P}$ \\
\hline & 2.E-04 & -0.349 & 0.450 & 5.E-06 & 0.044 & 0.747 & -0.033 & 0.034 & 0.046 & -0.012 & -0.012 & 0.093 \\
\hline & 0.972 & -1.990 & 2.677 & 4.747 & 5.334 & 15.293 & -3.338 & 1.196 & 3.165 & -0.315 & -0.834 & 2.335 \\
\hline & 0.995 & -2.157 & 2.949 & 1.321 & 0.659 & 5.267 & -0.633 & 0.634 & 1.114 & -0.208 & -0.224 & 1.213 \\
\hline \multirow[t]{4}{*}{ DJIA } & $\theta_{0}$ & $\theta_{1}$ & $\theta_{2}$ & $\omega$ & $\alpha$ & $\beta$ & $\alpha_{D J S}$ & $\beta_{D J S}$ & $\alpha_{E S I}$ & $\beta_{E S I}$ & $\alpha_{S P}$ & $\beta_{S P}$ \\
\hline & -1.E-04 & -0.337 & 0.358 & 8.E-07 & 0.034 & 0.871 & 0.103 & -0.003 & -0.005 & -0.002 & -0.029 & 0.058 \\
\hline & -0.483 & -0.690 & 0.739 & 1.753 & 3.247 & 29.567 & 7.567 & -0.084 & -5.338 & -0.395 & -2.806 & 3.087 \\
\hline & -0.465 & -0.575 & 0.615 & 3.820 & 1.152 & 13.690 & 3.575 & -0.046 & -2.239 & -0.271 & -1.140 & 1.905 \\
\hline \multirow[t]{4}{*}{ S\&P500 } & $\theta_{0}$ & $\theta_{1}$ & $\theta_{2}$ & $\omega$ & $\alpha$ & $\beta$ & $\alpha_{D J S}$ & $\beta_{D J S}$ & $\alpha_{E S I}$ & $\beta_{E S I}$ & $\alpha_{D J I}$ & $\beta_{D J I}$ \\
\hline & -3.E-05 & 0.903 & -0.911 & 4.E-07 & -0.010 & 0.435 & 0.057 & 0.328 & -0.008 & -0.018 & 0.063 & 0.415 \\
\hline & -1.715 & 19.822 & -21.132 & 0.126 & -0.441 & 3.056 & 1.995 & 2.157 & -1.142 & -0.611 & 2.462 & 2.919 \\
\hline & -0.689 & 7.748 & -8.145 & 0.950 & -0.129 & 0.924 & 1.406 & 0.976 & -5.854 & -0.458 & 0.834 & 1.038 \\
\hline
\end{tabular}

Table 3: VARMA-GARCH Spillover for Four Indexes

\begin{tabular}{|c|c|c|c|c|c|c|c|c|c|c|c|c|c|}
\hline \multirow{3}{*}{$\begin{array}{c}\text { Data } \\
\text { DJSI }\end{array}$} & \multirow{2}{*}{\multicolumn{3}{|c|}{ Conditional Mean }} & \multicolumn{10}{|c|}{ Conditional Variance } \\
\hline & & & & \multicolumn{4}{|c|}{ Own Effects } & \multicolumn{6}{|c|}{ Spillover Effects } \\
\hline & $\theta_{0}$ & $\theta_{1}$ & $\theta_{2}$ & $\omega$ & $\alpha$ & $\gamma$ & $\beta$ & $\alpha_{\text {ETHI }}$ & $\beta_{\text {ETHI }}$ & $\alpha_{D J I}$ & $\beta_{D J I}$ & $\alpha_{S P}$ & $\beta_{S P}$ \\
\hline \multirow[t]{3}{*}{ World } & 6.E-05 & -0.216 & 0.319 & 6.E-07 & -0.020 & 0.081 & 0.950 & 0.002 & -0.005 & 0.016 & -0.005 & -0.017 & 0.022 \\
\hline & 0.350 & -1.202 & 1.828 & 4.378 & -4.070 & 9.554 & 124.305 & 1.246 & -2.045 & 2.663 & -0.580 & -2.785 & 2.549 \\
\hline & 0.357 & -1.346 & 2.063 & 3.071 & -1.979 & 4.523 & 62.917 & 1.143 & -1.362 & 1.157 & -0.275 & -1.445 & 1.573 \\
\hline \multirow{4}{*}{$\begin{array}{c}\text { ESI } \\
\text { Global }\end{array}$} & $\theta_{0}$ & $\theta_{1}$ & $\theta_{2}$ & $\omega$ & $\alpha$ & $\gamma$ & $\beta$ & $\alpha_{D J S}$ & $\beta_{D J S}$ & $\alpha_{D J I}$ & $\beta_{D J I}$ & $\alpha_{S P}$ & $\beta_{S P}$ \\
\hline & 3.E-04 & -0.376 & 0.471 & 5.E-06 & 0.037 & 0.099 & 0.744 & -0.074 & 0.064 & 0.058 & -0.007 & -0.033 & 0.077 \\
\hline & 1.062 & -2.149 & 2.823 & 5.607 & 6.710 & 5.497 & 19.286 & -6.737 & 2.332 & 4.031 & -0.176 & -2.548 & 2.084 \\
\hline & 1.012 & -2.139 & 2.871 & 1.534 & 0.340 & 2.113 & 11.634 & -1.261 & 1.265 & 1.410 & -0.120 & -0.580 & 1.388 \\
\hline \multirow[t]{4}{*}{ DJIA } & $\theta_{0}$ & $\theta_{1}$ & $\theta_{2}$ & $\omega$ & $\alpha$ & $\gamma$ & $\beta$ & $\alpha_{D J S}$ & $\beta_{D J S}$ & $\alpha_{\text {ETHI }}$ & $\beta_{\text {ETHI }}$ & $\alpha_{S P}$ & $\beta_{S P}$ \\
\hline & 1.E-06 & 0.972 & -0.981 & 3.E-07 & -0.029 & 0.111 & 0.923 & 0.025 & 0.009 & 3.E-04 & -0.002 & -0.014 & 0.034 \\
\hline & 0.407 & 75.601 & -93.498 & 1.352 & -4.674 & 11.567 & 94.823 & 3.653 & 0.707 & 0.234 & -0.629 & -2.393 & 4.104 \\
\hline & 0.400 & 71.316 & -87.100 & 1.475 & -1.595 & 4.703 & 36.171 & 1.407 & 0.378 & 0.101 & -0.510 & -0.718 & 1.863 \\
\hline \multirow[t]{4}{*}{ S\&P500 } & $\theta_{0}$ & $\theta_{1}$ & $\theta_{2}$ & $\omega$ & $\alpha$ & $\gamma$ & $\beta$ & $\alpha_{D J S}$ & $\beta_{D J S}$ & $\alpha_{\text {ETHI }}$ & $\beta_{\text {ETHI }}$ & $\alpha_{D J I}$ & $\beta_{D J I}$ \\
\hline & -4.E-04 & -0.056 & 0.059 & -3.E-07 & -0.063 & 0.206 & 0.853 & 0.008 & 0.064 & -0.003 & 0.010 & 0.011 & 0.069 \\
\hline & -0.177 & -0.009 & 0.010 & -0.441 & -7.757 & 11.641 & 57.851 & 0.669 & 2.658 & -1.587 & 1.541 & 0.954 & 7.268 \\
\hline & -1.465 & -0.157 & 0.166 & -4.345 & -2.344 & 6.371 & 24.028 & 0.457 & 1.743 & -4.508 & 1.364 & 0.498 & 2.451 \\
\hline
\end{tabular}

Notes: The three entries corresponding to each parameter are their estimates, their asymptotic t-ratios, and the Bollerslev and Wooldridge (1992) robust t-ratios. DJS, ESI, DJI and SP refer to DJSI World, ESI Global, DJIA and S\&P500, respectively. 
Table 4: Conditional Correlations

\begin{tabular}{|lcccc|}
\hline VARMA-GARCH & DJSI World & ESI Global & DJIA & S\&P500 \\
\hline DJSI World & \multirow{2}{*}{1.000} & 0.841 & 0.667 & 0.721 \\
ESI Global & & 1.000 & 0.706 & 0.786 \\
DJIA & & & 1.000 & 0.934 \\
S\&P500 & & & & 1.000 \\
\hline
\end{tabular}

\begin{tabular}{|lcccc|}
\hline VARMA-AGARCH & DJSI World & ESI Global & DJIA & S\&P500 \\
\hline DJSI World & 1.000 & 0.834 & 0.668 & 0.714 \\
ESI Global & & 1.000 & 0.705 & 0.780 \\
DJIA & & & 1.000 & 0.927 \\
S\&P500 & & & & 1.000 \\
\hline
\end{tabular}

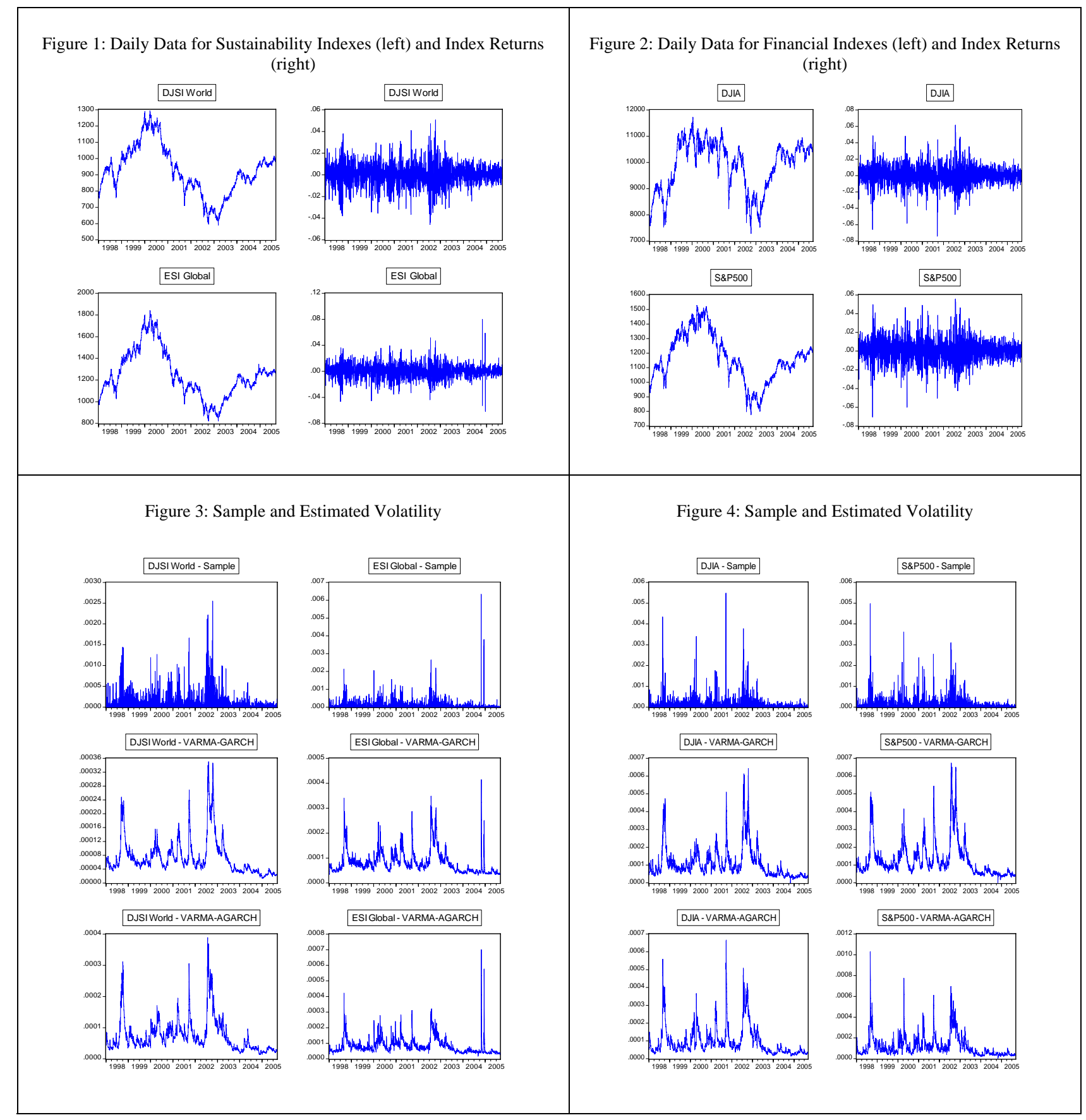

